\title{
Detection of Genetic Variation in Crop Plants
}

\section{Manu Kumar*}

Department of life science, Sogang University, Seoul, South Korea

Keywords: Genetic variations; Index score and genotype.

\section{Introduction}

Crop improvement techniques remain a major concern to plant breeders to address world food shortage. Several factors such as climate, weather, soil, edaphic and biological and more importantly crop genotype affect crop improvement for specific or general environment performance $[1,2]$. Crop genotype includes different crop forms of inbred or pure lines hybrids, landraces, wildraces germplasm accessions, cultivars or varieties $[3,4]$. These crop genotypes have diverse and wide origin and genetic background known as genetic diversity. Genetic diversity study is a major turnaround in understanding intra-specie crop performance leading to crop improvement. Information of crop performance in genetic diverse population reveals the real differences in the nature of genetic materials used.

\section{Metroglyph Analysis}

This is a semigraphic method of studying variability in a large number of germplasm lines taken at a time. This technique was developed by Anderson [5] to investigate the pattern of morphological variation in crop species.

The semi graphic method consists of the following steps.

\section{Plotting of glyph on the graph}

A small circle by which the position of a genotype or line is represented on the graph is called glyph. For plotting of glyph on the graph two characters having high variability are chosen. One of them is used on the $\mathrm{X}$ - axis and the other on the $\mathrm{Y}$-axis. The mean values of $\mathrm{X}$ for each genotype are plotted on the graph against the mean values of Y. Thus each line occupies a definite position on the graph called glyph.

\section{Depiction of variation}

Variation for remaining characters of each genotype is displayed on the respective glyph by rays. Each character occupies a definite ray position. Variation for each character is depicted by the length of ray. Thus, the length of ray for a particular character on the glyph may be short or medium or long depending on the index value of a genotype.

\section{Construction of index score}

For this purpose, the variation for each character is divided into three groups, viz., low, medium and high. The genotypes with low, medium and high values are given index score 1,2 and 3, respectively. The worth of a genotype is calculated by adding the index values of all the characters. Thus, the maximum and minimum score of an individual will be $3 n$ and $n$ respectively, where $n$ is the total number of characters included in the study.

\section{Analysis of Variation}

The $\mathrm{X}$ - and $\mathrm{Y}$-axes are divided into three groups, viz., low, medium and high. The maximum number of groups or clusters will be nine. The variation is analyzed for various traits within the group and between the groups. The genotypes for use as parents in the hybridization program should be chosen from different groups representing wide genetic variability.

\section{$D^{2}$ statistics}

The concept of $\mathrm{D}^{2}$ statistics was originally developed by Mahalanobis [6]. Genetic diversity arises due to geographic separation or due to genetic barriers to cross ability.

The selected genotypes are evaluated in replicated field trial and observations are recorded on various quantitative characters.

First variances for various characters and co-variances for their combinations are estimated.

(a) Computation of $\mathrm{D}^{2}$ values and testing their significance against the table value of $\chi^{2}$ for $p$ degrees of freedom, where $p$ is the total number of characters. If the calculated value of $\mathrm{D}^{2}$ is higher than table value of $\chi^{2}$ it is considered significant and vice versa.

(b) Finding out the contribution of individual character towards total divergence.

(c) Grouping of different genotypes into various clusters

(d) Estimation of average distance at (a) intra-cluster and (b) intercluster levels and

(e) Construction of cluster diagram

In $\mathrm{D}^{2}$ analysis, a diagram is constructed with the help of $\mathrm{D}^{2}$ values which is known as cluster diagram. The square roots of average intra and inter cluster $\mathrm{D}^{2}$ values are used in the construction of cluster diagram. This diagram provides information on the following aspects.

1 . The number of clusters represent the number of groups in which a population can be classified on the basis of $\mathrm{D}^{2}$ analysis

2. The distance between two clusters is the measure of the degree of diversification. The greater the distance between two clusters the greater the divergence and vice versa.

The genotypes falling in the same cluster are more closely related than those belonging to another cluster.

\section{References}

1. Kumar M (2013) Crop Plants and Abiotic Stresses. J Biomol Res Ther 3: e125

2. Aremu CO, Adebayo MA, Ariyo OJ, Adewale BD (2007) Classification of genetic diversity and choice of parents for hydridization in cowpea vigna unguiculata (L) walip for humid savanna ecology. African journal of biotechnology 6: 23332339.

*Corresponding author: Manu Kumar, Department of life science, Sogang University, Seoul, South Korea, E-mail: manukumar7@sogang.ac.kr

Received April 16, 2015; Accepted April 19, 2015; Published April 27, 2015

Citation: Kumar M (2015) Detection of Genetic Variation in Crop Plants. J Biomo Res Ther 4: e140. doi:10.4172/2167-7956.1000e140

Copyright: (C) 2014 Kumar M. This is an open-access article distributed under the terms of the Creative Commons Attribution License, which permits unrestricted use, distribution, and reproduction in any medium, provided the original author and source are credited. 
3. Akbar AA, Kamran M (2006) Relationship among yield components and selection criteria for yield improvement of Safflower-Carthamustinctorious $L$. J Appl Sci 6: 2853-2855.

4. Aremu CO, Adebayo MA, Oyegunle M, Ariyo JO (2007) TRhe relative discriminatory abilities measuring Genotype by environment interaction in soybean (Glycine max). Agricultural journal 2: 210-215.
5. Anderson E (1957) A SEMIGRAPHICAL METHOD FOR THE ANALYSIS OF COMPLEX PROBLEMS. Proc Natl Acad Sci U S A 43: 923-927.

6. Mahalanobis PC (1928) A statistical Study at Chinese head measurement. J Asiatic Soc Bengal 25: 301-377. 